\title{
RECONSTRUCTION, ADAPTER DESIGN AND APPLICATION OF A NOKIA PUMA 560 ROBOT'S GRIPPER ON A ROBOT CELL INTEGRATED KUKA KR5 INDUSTRIAL ROBOT
}

\author{
Gábor VONA, ${ }^{1}$ Antal APAGYI, ${ }^{2}$ Timotei István ERDEI, ${ }^{3}$ Géza HUSI ${ }^{4}$ \\ University of Debrecen, Faculty of engineering, Department of Mechatronics, Debrecen, Hungary \\ ${ }^{1}$ bjgabi@gmail.com \\ ${ }^{2}$ apagyi.toni@gmail.com \\ ${ }^{3}$ timoteierdei@eng.unideb.hu \\ ${ }^{4}$ husigeza@eng.unideb.hu
}

\begin{abstract}
This summary details the steps that were necessary to fasten a Nokia Puma 560's gripper to a KUKA KR5 industrial robot found at University of Debrecen, Department of Mechatronics and also demonstrates its applications in the robot cell designed around its usage. It also includes the inspection and reconstruction of said gripper, and the 3D designing of its adapter. The adapter is intended for the KUKA KR5 robot, which is later manufactured using PRO-PLA 3D printing. The KUKA KR5 will also have a robot cell designed and built around it, for educational purposes.
\end{abstract}

Keywords: SketchUp make, 3D modelling, gripper, robot .

\section{Introduction}

In the „Cyber-Physical and Intelligent Robot Systems Laboratory” of the building mechatronics centre of University of Debrecen, new manufacturing tools have been developed, which are able to satisfy all conditions set by industry 4.0 [1]. In the industrial sector, there are numerous devices which are mechanically intact, but are missing their controllers, or their existing controllers are only programmable with obsolete methods [2]. There are even such reference examples, in which the given hardware had to be "renovated" to ensure productive functioning [3].

\section{Evaluation of the Nokia Puma robot}

\subsection{The robot's state}

The industrial robot resides outside, in a place protected from rain, under a roofed hallway. The rainy, and humid winter weather however puts the robot at risk of corrosion. The robot arm has been discarded for many years now, is in a non-functional state, and, in places, shows signs of corrosion.

Long term goals include the complete reconstruction of the construction, and the creation of a new control system. However, designing and realizing the „Cyber-Physical and Intelligent Robot Systems Laboratory” was a higher priority at the time. In addition, the number of suitable tasks intended for the KUKA KR5 is also minimal, which is in part due to the lack of variety (and amount) of grippers. In light of all this, the Nokia PUMA 560 's gripper shall be renovated.

\subsection{The gripper's type and state}

Due to corrosion and lack of lubrication, it was impossible to open the jaws of the gripper by using human force. The KUKA KR5 robot's 6[mm] outside diameter pneumatic tube was chosen, because its parameters were most suitable for the gripper's functions. Unlike this gripper's threaded fittings, the connectors used on the KR5 are quick-connect pneumatic fittings. The threaded fittings are shown in Figure 1. 


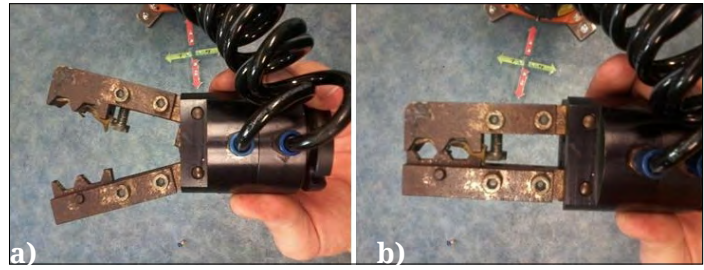

Figure 1. Gripper's opened state and closed state

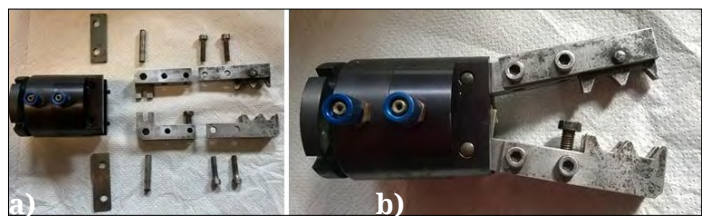

Figure 2. Before and after assembly

It was clear that accessing the internal piston, removing corrosion, ensuring proper lubrication, and complete removal of the mechanism's arms were all necessary. After being lubricated, with every opening and closing the piston moved faster. After a few dozen repetitions, the pneumatic cylinder's movement became smooth and consistent.

\subsection{Controlling the pneumatic gripper}

In order to control the gripper from the KUKA KR5 robotic arm, thecompressed airflow must be controlled by an electro-pneumatic valve. To achieve this, a Japanese-made H040-4E2 [4] piloted bi-stable valve was chosen.

The valve is controlled from the KUKA KR5's control cabinet, using a previously developed controller, which uses programming similar to PLCs [5]. The device is optically coupled (galvanically separated) and has a relay output. This made it ideal for switching the necessary $24 \mathrm{~V}$ voltage level.

\section{Maintenance of the gripper}

Thanks to its simple construction, the gripper can be maintained with only basic tools. During the usage of the available tools and instruments, cost-efficiency was the key aspect.

Surface corrosion was removed using different grade sandpaper sheets, with the exception of the precision wear-resistant inserts. General degreasing and cleaning was done by using brake cleaner spray.

During assembly, parts were readded in reverse order of disassembly. The disassembled gripper can be observed on Figure 2 .

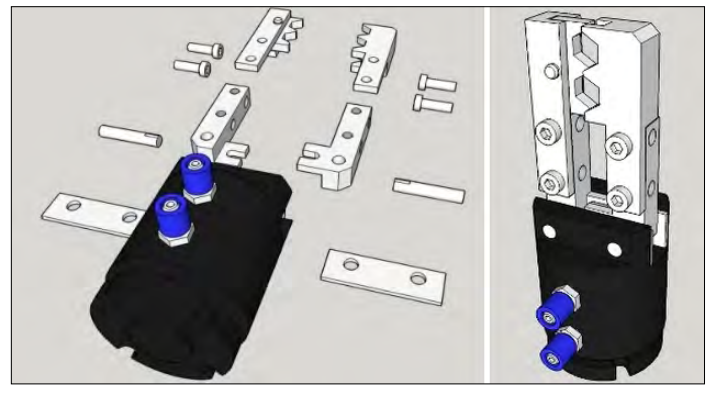

Figure 3. Finished 3D model

The moving parts of the gripper were lubricated, which serves multiple purposes, such as ensuring quick opening and closing, preventing corrosion, preventing accelerated wear surfaces that are in contact with each other, and ensuring error-free operation. The assembled gripper can be observed in figure 6 .

The gripper is operated at a nominal pressure of 3.2 bar. The gripped object was chosen to be a $25 \times 25 \mathrm{~mm}$ aluminum cube.

\section{Making of the gripper's 3D model}

Measurements of the grippers' parts were made with precision calipers, which had a measurement range of 0-150 $\mathrm{mm}$, and precision of $0.05 \mathrm{~mm}$.

The 3D model was created in the freely downloadable software, SketchUp Make, which is user friendly. Its online warehouse offers many useful plugins for download [6].

For future use, the gripper's 3D module was created. For easier modelling, and later modification of the component sizes, every part was modelled separately, which is shown in Figure 3.

It is also possible to design additional parts.

The separately created parts can be added into a group, for easier movement. Figure 5 . shows the gripper with its parts assembled.

As the 3D model of the gripper is entirely finished - and the separately modelled parts are grouped up - it is possible to design new inserts for the gripper, suitable for all kinds of workpiece shapes and sizes. With the emergence of rapid prototyping technologies, manufacturing these inserts can be done relatively quickly, and easily.

\section{KUKA KR5 adapter design for the reconstructed gripper}

\subsection{Design and 3D modelling of the adapter}

The KUKA KR5 has similar placement of holes, however, there is a difference of $1 \mathrm{~mm}$ between 
these holes, and the diameter of the used screws also differs. As a consequence, a part was necessary to bridge these differences, and connects the gripper with the robotic arm. The adapter was designed with a wall thickness of $5.5 \mathrm{~mm}$, which was found to be the optimal size for cost effectiveness, and strength.

To ensure connection between the two adapters, M5 screws are used every side. The inner adapter features a hex nut holder, which can also hold locking nuts. The adapters designed for connecting the gripper to the robot arm can be seen on Figure 4.

\subsection{Preparation of the 3D model for printing}

To be able to open the finished files in Repetier Host, the files had to be exported to .stl format. The Repetier Host is one of the many development environments used in 3D printing [7]. A plugin is available in the SketchUp Make online warehouse to allow the program to export the finished 3D models to the desired .stl format [6]. The parameters were set up, then the slicing was done with CuraEngine, which is a built-in part of the program. The results are available after the slicing simulation. The planned printing material was PRO PLA, as similarly easy to print as PLA, but its impact resistance is much greater. PRO PLA printing does not require a heated bed, the extruder temperatures should be in the $185-215{ }^{\circ} \mathrm{C}$ range. The material does not shrink during cooling and is not flammable [8].

Printing of the two components (with a $50 \%$ fill rate) took 6 hours and 21 minutes, and $29.25 \mathrm{~m}$ filament. Using PLA PRO, this translates to a material cost of approx. $659 \mathrm{ft}$. The total weight of the gripper with the adapter and its fastening components is $750 \mathrm{~g}$. The adapters are symmetrical, so they may be fastened in any orientation. The secured adapters can be seen in Figure 5 .

The secured tool was used to carry out material handling tasks, during which the KUKA KR5 robot uses the gripper, with the collaboration of a Flexling conveyor [9], to demonstrate an industrial process. As a workpiece, a $\emptyset 12 \times 40.6 \mathrm{~mm}$ size cylindrical workpiece was chosen, to utilize the gripper's specialised insert.

\section{Application of the gripper in the KUKA KR5 based robot cell}

GA manufacturing cell was designed and built around the KUKA KR5, to be used for educational purposes. As the manufacturing cells are separate and easy to move, they are mobile, as repre-

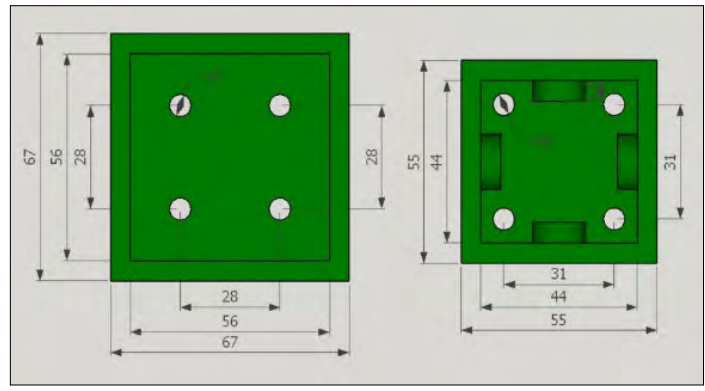

Figure 4. Top-down view of the adapter

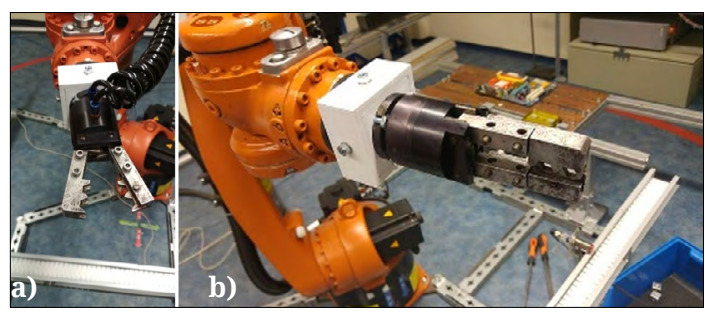

Figure 5. Secured reconstructed gripper

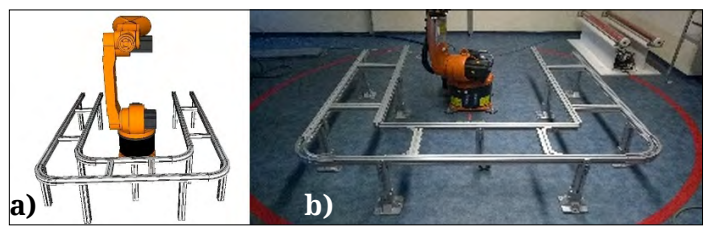

Figure 6. The built cell and its model

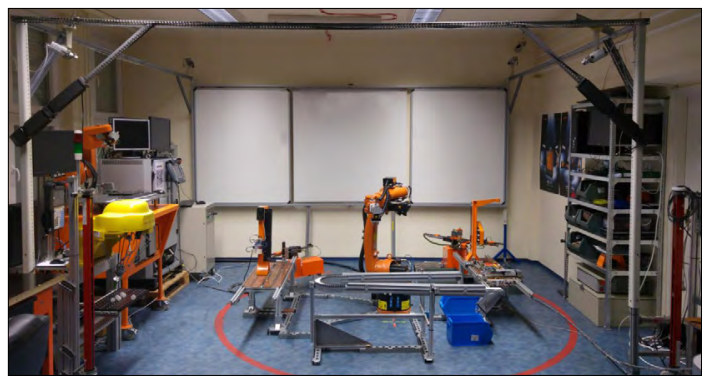

Figure 7. The complete cell [10]

sented by Figure 6 . a). The structure consists of $40 \times 40 \mathrm{~mm}$ aluminum profiles. These profiles are secured by internal hex screws and T-nuts. The stands are secured by M8 hex screws to the aluminum profiles.

After construction, a 3D model including the cell and the industrial robot was created, to ease further additions to the system. The model can be seen in Figure 6. b).

Four industrial cameras were placed to observe the area surrounding the industrial robot. (Figure 7.). The cameras' images can be seen on monitors placed on nearby surfaces. With their help, 
the cell can be observed from different angles, while it also assists in denying entry to unauthorized personnel. The outer cell helps with cable management of the different devices within the cell. This assists in avoiding accidents, vandalism, or excessive damage in case of malfunction.

\section{Conclusions}

The given task was completed. The gripper is suitable for educational purposes, although due to its worn state, it's recommended to use it at pressures greater than 3 bar, to increase closing speed. These advancements also open ways for further expansion of possible tasks.

The total costs of the reconstruction were low and did not exceed a $1000 \mathrm{ft}$ value, thanks to the intact state of the cylinder's seals. Thus, the reconstruction was magnitudes cheaper than the purchase of a new effector. A brand-new SMC HMT2 two-armed gripper of similar construction would cost approximately $90000 \mathrm{ft}$, without the inserts. Said gripper is also $200 \mathrm{~g}$ heavier, and its fastening to the industrial robot itself would also prove more difficult [11].

Because the angle gripper has a greater gripping range than the current gripper of the KUKA robot, there's a far wider range of completable tasks. In the future, certain upgrades are also possible with the usage of sensors. The gripper can be fitted with new inserts, which can be created by 3D modelling programs, and manufactured by 3D printing, or other metalworking processes.

\section{Acknowledgements}

I'd like to express my thanks to Dr. habil. Husi Géza, head of department, and to my consultant Erdei Timotei István, for their help provided during the entirety of this work.

\section{References}

[1] Erdei T. I., Molnár Zs., Obinna N. C., Husi G.: Cyber physical systems in mechatronic research centre. MATEC Web Conf. 126, 2017.

[2] Erdei T. I., Molnár Zs., Husi G.: Robot visual and virtual control technology In industrial environment. WoS publication, International Symposium on Small-Scale Intelligent Manufacturing Systems (SIMS ), Narvik, NORWAY- IEEE, Jun 21-24, 2016.

[3] Obinna N. C., Erdei T. I., Molnár Zs., Husi G.: Investigating Configuration Space Singularities of KUKA KR5. International Mechatronical Student micro-Conference IMS $\mu C^{\prime} 2016$.

[4] HUMPHREY H040-4E2. (accessed on: 2 December 2018)

http://www.smcpneumatics.com/MHT2-32D.html

[5] Erdei T. I., Molnár Zs., Obinna N. C., Husi G.: AGV cyber physical navigation system. FMTÜ - XXII. International Scientific Conference of Young Engineers - Kolozsvár, 23-24.03.2017.

[6] SktechUp Make. (accessed on: 2 December 2018) https://www.sketchup.com/download/make.

[7] Repetier- Host. (accessed on: 2 December 2018). https://www.repetier.com/

[8] 3D Jake, PLA PRO. (accessed on: 2 December 2018).

https://www.3djake.hu/spectrum/pla-pro-bluelagoon

[9] Flexlink. (accessed on: 2 December 2018). https://www.flexlink.com/en/home/

[10] Erdei T. I.: Ipar 4.0 robot labor fejlesztése LEAN módszertan integrálásával \& gyártási rendszer folyamatok optimalizációja Mixed-Reality alapon: [01 03 2019].

[11] SMC Pneumatics, SMC MHT2-32D. (accessed on: 2 December 2018). http://www.smcpneumatics.com/MHT2-32D.html. 